\title{
The Relationship Between English Language Proficiency And Academic Performance of University Students - Should Academic Institutions Really be Concerned?
}

\author{
Pauline Ghenghesh \\ Department of English Language, the British University in Egypt, El Sherouk City, Cairo, Egypt \\ E-mail: paulineghenghesh@yahoo.co.uk
}

Received: 29-07-2014

Accepted: 04-10-2014

Published: 01-03-2015

doi:10.7575/aiac.ijalel.v.4n.2p.91

URL: http://dx.doi.org/10.7575/aiac.ijalel.v.4n.2p.91

\begin{abstract}
This paper aims to investigate if there is a relationship between English language proficiency and the overall academic performance of Preparatory Year students in three faculties: Engineering, Business (including Business Administration, Economics and Political Science) and Informatics and Computer Science. Data was obtained from the Student Record System of 566 students and three sets of statistical analysis were performed. The results indicated that there is a significant but moderate positive relation between the students' proficiency in English and their overall academic success. Specifically, the higher the English proficiency of students on entry to the university, the better they performed in their degree area courses as well as in their English levels.
\end{abstract}

Keywords: proficiency; performance; language; instruction; competence

\section{Introduction}

One of the most important aspects of university education for English as a Foreign Language (EFL) students is a high level of proficiency in English to help them progress through their education. Proficiency can be defined as "the ability of students to use the English language to make and communicate meaning in spoken and written contexts while completing their university studies" (DEEWR, 2009, p.1). Therefore, an EFL student must be able to read, write, listen and speak effectively. Moreover, "English prepares students for meaningful instruction and academic performance in academic subjects taught using the English language" (Kong et al., 2012, p.20). Unfortunately, students who lack the necessary language skills will not be able to engage in the learning process and will struggle to pass their academic courses. The impact of university failure can also result in low self-esteem, frustration, de-motivation and disinterest in attending lectures and tutorials.

For those students whose mother tongue is not English and wishing to enter a university in the UK, USA, Canada, Australia, Hong Kong and New Zealand as well as other universities and colleges world-wide will need to demonstrate their ability to perform in the four language skills (reading, writing, listening and speaking) by taking a test. The International English Language Testing System (IELTS) is the most commonly recognised test world-wide. The test results are reported on a band scale from 1 to 9 where 1 is a non-user to 9 which is an expert user. English language requirements for undergraduate degrees for UK university admission is an overall score ranging from $6.0-6.5$ (Study Connect International, 2014) and this will be higher for courses such as medicine.

At the British University in Egypt (BUE) the majority of students are Egyptian. Literary Arabic is the official language, with Egyptian Arabic the vernacular. English, however, is the medium of instruction in all departments and faculties at the university. Therefore, to be admitted to the university, all students needed to score 105 to 119 (Pre-Intermediate) on the Oxford Placement Test which is equivalent to IELTS 3. However, since the writing of this paper, with the exception of the Faculty of Nursing, the entry score has been increased to 120 to 134 (Intermediate) which is equivalent to IELTS 4. English courses at the BUE are taken alongside the students' degree area courses as language support and students must pass them to progress to the next level. In addition, passing English courses has become a condition of progression in the faculties (i.e. Intermediate English is a condition of progression to Degree Year 1; Upper Intermediate English to Degree Year 2; and Advanced English to Degree Year 3). Students entering the BUE come from three main educational backgrounds: Thanaweya Amma, American High School Diploma and IGCSE/GCSE.

Interestingly, Murray (2010) states that "despite meeting the English language entry criteria of their receiving institutions, many NESB students still struggle to cope with the linguistic demands of their degree courses as a result of inadequate levels of proficiency" (p.61). Along similar lines, reporting on the weaknesses of Yemeni Arab students Abbad (1988) states that "in spite of the low proficiency level in English of most applicants they are accepted into the department" (p.15). In addition, there has been concern and debate over the level of the English language proficiency of students upon entry to universities across Australia and in other countries as well (Barthel, 2012). Therefore, based on the above findings and the recommendations of Dooey (1999) who suggested that "each receiving institution make its 
own informed decision regarding the appropriate level of English required for the different courses it offers" (p.115) this research was conducted.

\section{Review of the Literature}

From the available published research findings in different parts of the world, EFL students can be disadvantaged in their performance at school, college and university because of their poor proficiency level in English. To shed more light on this, a number of researchers have investigated the effects of English language proficiency on the academic performance of students. With regard to Arab students Suleiman (1983) argues that "inadequate mastery of the four language skills; namely listening, speaking, reading and writing" (p.129) hinders the progress of Arab students at university level. Zughoul (1987) agrees with Suleiman's point of view in questioning the linguistic competence of incoming freshmen students. Mukattash (1983) also states that university students' are unable to use English correctly and appropriately both inside and outside the classroom when dealing with academic and everyday topics. Similarly, in a study conducted on students at a college in Oman it was reported that the lack of proficiency in English does affect their performance in engineering courses (Sivaraman et al., 2014). Other research findings at two tertiary education institutions in Oman also show a strong, positive relationship between English language performance and GPA (Roche, \& Harrington, 2013).

In addition, the results of a correlational study conducted by Sahragard \& Baharloo (2009) on Iranian university students majoring in English Language and Literature found that students who are more competent in English language are more successful in their classes. Furthermore, in an attempt to determine whether there was a significant relationship between Iranian EFL college students' language proficiency and their academic achievement, the results of a study conducted by Sahragard et al. (2011) demonstrated that the students who scored higher on the language proficiency test had better GPA scores. Other studies from Iran have reported similar findings. For example, Maleki and Zangani (2007) found a significant connection between proficiency and grade point averages of academic achievement of EFL students majoring in English translation while Sadeghi et al. (2013) found that proficiency in English could significantly influence academic achievement of medical students.

Studies from Australia have also reported similar findings. For example, a study conducted on the impact of IELTS Scores on Performance at an Australian university has reported a significant and positive relationship between language proficiency of international university students and their overall academic performance as measured by their GPA (Feast, 2002). These results appear to be consistent with a study conducted by researchers at the University of Melbourne in which they found a moderately strong correlation between the students GPA and IELTS scores (Hill et al., 1999).

In other studies from higher education institutions in Nigeria, India, USA and Malaysia, researchers found that English language proficiency and academic performance are directly related (Aina et al., 2013; Kumar, 2014; Xu, 1991; AlHaddad et al., 2004).

Along similar lines, students' achievement in school also depends upon their level of proficiency in the language of instruction (Wilkinson \& Silliman, 2008). Research findings from school contexts have been reported. For instance, the results of a study conducted by Wilson and Komba (2012) at a secondary school in Tanzania illustrated that the more proficient students are in English the better they are in academic subjects. This finding is in agreement with studies conducted on EFL Nigerian students which revealed that there is a significant correlation between English language proficiency and academic achievements of the subjects studied (Fakeye, 2014; Jekayinfa, 1991).

\section{Aims of the study}

Since obtaining a score of Pre-Intermediate on the Oxford Placement Test for the Faculty of Nursing and Intermediate for all other departments and faculties as a prerequisite for admission to the BUE, the aims of this study were to: a) investigate whether there is a relationship between the English language proficiency of Preparatory Year students in the Faculties of Engineering, Business (including Business Administration, Economics and Political Science) and Informatics and Computer Science and their academic achievement and b) whether the students' educational backgrounds have an impact on their academic performance. The study was guided by the following research questions:

1. Is there a relationship between English language proficiency and GPA?

2. Does English language proficiency have an impact on achievement in English?

3. Is there a relationship between educational backgrounds and academic performance?

\section{Methodology}

\subsection{Procedure and Data Collection}

The researcher obtained permission to carry out this research from the Research Committee in the English Department at the BUE.

Data was collected from the Student Record System of 566 students and prepared in Excel sheets by an administrative member of staff in the Quality and Validation Office at the BUE. Included in this data gathering were: ID numbers and names of students in the Preparatory Year, their faculties, educational backgrounds, English placement test scores, English scores and their GPA scores. Students' demographic characteristics are shown in Table 1.

\subsection{Data Analysis}

The data that was obtained from Quality and Validation Office was computer coded and processed with the Statistical Package for the Social Sciences (SPSS) version 13.0 and three sets of statistical analysis were performed. Firstly, a 
correlation analysis of the students' English levels and their year average for the whole cohort. Secondly, a cross tabulation of the English levels and the grade bands (i.e. A, B, C, D \& F) obtained at the end of the academic year. Thirdly, descriptive statistics, that is the mean and standard deviation for the students' educational backgrounds on GPA scores.

Table 1. Students' demographic characteristics

\begin{tabular}{llll}
\hline & & Frequency & $\mathbf{\%}$ \\
\hline Faculty & Business & 414 & 73.1 \\
& Engineering & 126 & 22.3 \\
& ICS & 26 & 4.6 \\
\hline Education background & Thanaweya Amma & 192 & 33.9 \\
& American Diploma & 197 & 34.8 \\
& IGCSE/GCSE & 113 & 20 \\
& Other certificates & 64 & 11.3 \\
\hline English level & Pre-Intermediate & 70 & 12.4 \\
& Intermediate & 174 & 30.7 \\
& Upper Intermediate & 164 & 29 \\
& Advanced & 158 & 27.9 \\
\hline
\end{tabular}

\section{Results}

\subsection{Relationship between English level and year average}

A correlation analysis was conducted to identify if there is a relationship between the English language proficiency of students upon entry to the university and their academic achievement (Grade Point Average). In order to interpret the size of the value of the Pearson correlation (r), Cohen (1988) has suggested the following guidelines. See Table 2 below.

Table 2. Determining the strength of the relationship between variables

\begin{tabular}{lll}
$\mathrm{r}=.10$ to .29 or $\mathrm{r}=-.10$ to -.29 & low \\
$\mathrm{r}=.30$ to .49 or $\mathrm{r}=-.30$ to -.49 & medium \\
$\mathrm{r}=.50$ to 1.0 or $\mathrm{r}=-.50$ to -1.0 & high \\
\hline
\end{tabular}

The results of the first analysis revealed a significant but moderate positive relation between the English language proficiency of the students and their academic achievement for the whole cohort. As shown in Table 3 the correlation coefficient (r) was .349. This shows that English proficiency is a determinant of academic success.

Table 3. Correlation analysis of English level and year average for the whole cohort

\begin{tabular}{llcc}
\hline Variables & English level & $\begin{array}{c}\text { Year average } \\
\text { (including } \\
\text { English \& } \\
\text { excluding } \\
\text { re-sit) }\end{array}$ \\
\hline English level & Pearson Correlation & 1 & $.349^{* *}$ \\
& Sig. (2-tailed) & 566 & .000 \\
& $\mathrm{~N}$ & $.349^{* *}$ & 566 \\
\hline Year average & Pearson Correlation & .000 & 1 \\
(including English & Sig. (2-tailed) & 566 & 566 \\
\hline excluding re-sit) & $\mathrm{N}$ & & \\
\hline
\end{tabular}

\footnotetext{
**. Correlation is significant at the 0.01 level (2-tailed).
} 


\subsection{Crosstabulation of English level and grade bands}

The results of the second analysis show the cross tabulation of the English levels and the grade band obtained at the end of the academic year (See Table 4). As shown, students who entered Pre-Intermediate and Intermediate had the highest percentage of failure rate with a grade $\mathrm{F}$ which is less than $40 \%$. Besides this, they also had the lowest number of A's (70\% and above) and B's (60-69\%) in comparison to students in the higher level modules (Upper Intermediate and Advanced). Furthermore, a comparison of Upper Intermediate and Advanced students' shows that overall the latter are performing better. This demonstrates that as the student's English proficiency increases so does their academic success.

Table 4. English level and grade bands

\begin{tabular}{|c|c|c|c|c|c|c|c|c|}
\hline \multirow{2}{*}{\multicolumn{3}{|c|}{ English Level }} & \multicolumn{5}{|c|}{ Average Categories } & \multirow[b]{2}{*}{ Total } \\
\hline & & & Less than 40 & $40-49$ & $50-59$ & $60-69$ & 70 or above & \\
\hline & \multirow[t]{2}{*}{ Pre-intermediate } & Count & 39 & 15 & 11 & 5 & 0 & 70 \\
\hline & & $\%$ within English Level & $55.7 \%$ & $21.4 \%$ & $15.7 \%$ & $7.1 \%$ & $.0 \%$ & $100.0 \%$ \\
\hline & \multirow[t]{2}{*}{ Intermediate } & Count & 65 & 50 & 38 & 15 & 6 & 174 \\
\hline & & $\%$ within English Level & $37.4 \%$ & $28.7 \%$ & $21.8 \%$ & $8.6 \%$ & $3.4 \%$ & $100.0 \%$ \\
\hline & \multirow[t]{2}{*}{ Upper Intermediate } & Count & 42 & 39 & 44 & 19 & 20 & 164 \\
\hline & & $\%$ within English Level & $25.6 \%$ & $23.8 \%$ & $26.8 \%$ & $11.6 \%$ & $12.2 \%$ & $100.0 \%$ \\
\hline & \multirow[t]{2}{*}{ Advanced } & Count & 31 & 29 & 40 & 28 & 30 & 158 \\
\hline & & $\%$ within English Level & $19.6 \%$ & $18.4 \%$ & $25.3 \%$ & $17.7 \%$ & $19.0 \%$ & $100.0 \%$ \\
\hline \multirow{2}{*}{\multicolumn{2}{|c|}{ Total }} & Count & 177 & 133 & 133 & 67 & 56 & 566 \\
\hline & & $\%$ within English Level & $31.3 \%$ & $23.5 \%$ & $23.5 \%$ & $11.8 \%$ & $9.9 \%$ & $100.0 \%$ \\
\hline
\end{tabular}

To shed more light on the above findings, as illustrated in Figure 1, the bar graph shows normal distribution of data for the Advanced English module as it fits a bell-shape curve. This finding implies that Advanced is the ideal level for student entry to the university to ensure academic success and for students to obtain the highest grades.

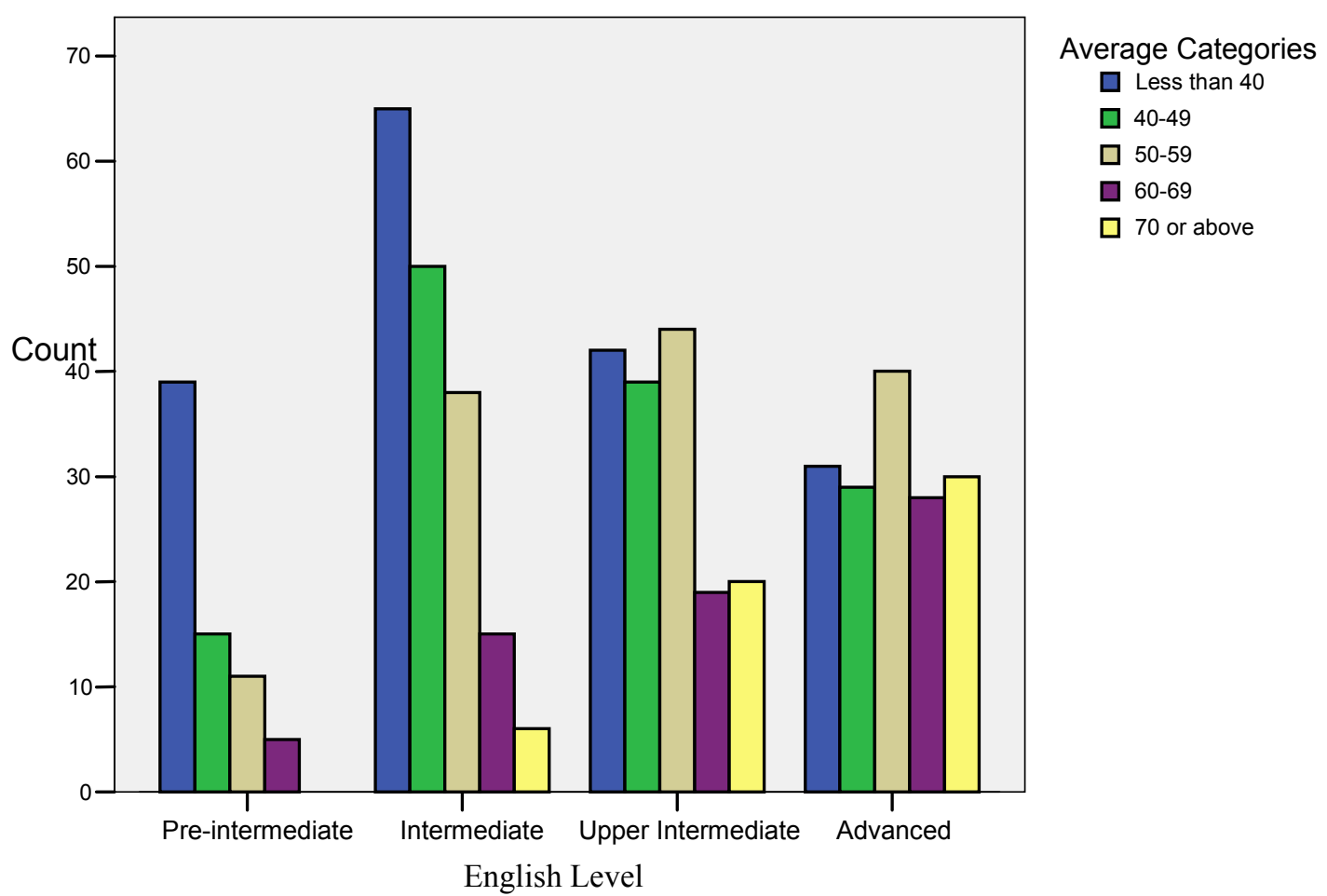

Figure 1. Bar graph of English level and grade bands

\subsection{Educational backgrounds and year average}

A third analysis was performed on the relationship between the students' educational backgrounds and their year average by descriptive statistics (See Table 5). With regard to the results of the three main educational backgrounds 
(Thanaweya Amma, American High School Diploma and IGCSE/GCSE), the mean score of Thanaweya Amma students is 43.393 with a standard deviation of 16.2193. Their scores range from 3.0 to 80.0. The average score for American High School Diploma students is 44.182 with a standard deviation of 14.2073. Their score varies from 2.0 to 84.0. The mean of IGCSE/GCSE is 58.949 with a standard deviation of 14.3287 and their GPA's vary from 18.0 to 96.0. Overall, the results show that students coming from Thanaweya Amma and American High School Diploma educational backgrounds are weaker than IGCSE/GCSE students with regard to academic achievement since both groups have received the lowest minimum scores and mean scores.

Table 5. Descriptive statistics for educational backgrounds on GPA scores

\begin{tabular}{lrrrrr}
\hline Certification Type & $\mathrm{N}$ & Mean & Std. Deviation & Minimum & Maximum \\
\hline Thanaweya Amma & 192 & 43.393 & 16.2193 & 3.0 & 80.0 \\
American Diploma & 197 & 44.182 & 14.2073 & 2.0 & 84.0 \\
IGCSE/GCSE & 113 & 58.949 & 14.3287 & 18.0 & 96.0 \\
Other Certificates & 64 & 48.391 & 15.7984 & 1.0 & 80.0 \\
Total & 566 & 47.338 & 16.2275 & 1.0 & 96.0 \\
\hline
\end{tabular}

\section{Discussion}

In response to the first research question (Is there a relationship between English language proficiency and GPA?), the result of the correlation analysis for the whole cohort as presented in Table 3 showed that there is a positive relationship between English language proficiency and academic achievement (GPA) at the 0.01 level. This finding illustrates that there is a direct relationship between these two variables and that English proficiency is a determinant of academic success for students at the BUE. This finding is in accordance with other research findings (Maleki \& Zangani, 2007; Sivaraman et al., 2014; Sadeghi et al., 2013; Roche \& Harrington, 2013) amongst others. Since English is the medium of instruction at the BUE, for students to be able to engage effectively in their academic studies and perform well, they must be able to read, write, listen and speak at a level appropriate to their studies on entry to the university.

With regard to the second research question (Does English language proficiency have an impact on achievement in English?), this study presented evidence to show that as the student's English language proficiency increases so does their academic success. This finding is in accordance with the results of other studies (Sahragard et al., 2011; Maleki \& Zangani (2007); Sadeghi et al., 2013). As shown in Table 4, comparing the four English levels (PreIntermediate, Intermediate, Upper Intermediate and Advanced) with grade bands (A, B, C, D \& F), students entering the university at the Upper Intermediate and Advanced levels have performed better than those in the lower English levels. However, comparing Upper Intermediate with Advanced students' the latter are performing better as they have the highest percent of students obtaining A's and the lowest percent of failing students. The entry score for the Advanced level is 150 and above on the Oxford Placement Test which is equivalent to IELTS 6.5. This finding is therefore consistent with the English language requirements for undergraduate degrees for UK university admission as an overall score ranging from 6.0 - 6.5 is required (Study Connect International, 2014). The band descriptor for a score of 6.0 - 7.0 on IELTS is a person can use and understand fairly complex language. Such a score therefore would enable a student to complete a course of study successfully as he/she can be fully engaged in the learning process.

With respect to the third research question (Is there a relationship between educational backgrounds and academic performance?), another important finding to report from this study is the student's educational backgrounds on GPA scores. As presented in Table 5, IGCSE/GCSE students have the highest mean score followed by American High School Diploma and Thanaweya Amma respectively. This result demonstrates that there is a relationship between schools and educational backgrounds. Similarly, a key finding from a study conducted in Australia is that schools have an impact on the academic performance of university students (Win \& Miller, 2004). To shed more light on this finding, for BUE students to be able to fully and successfully participate in lectures and tutorials and achieve academically across content areas, they should be proficient in English. Therefore, it seems that American High School Diploma and Thanaweya Amma education systems have not been as successful as the IGCSE/GCSE education system in preparing students for university study.

A possible factor for this finding is that English language skills are important parts of the IGCSE/GCSE curriculum. Each exam tests the knowledge of each subject a student takes through the medium of English. Therefore, schools offering this curriculum would need to ensure that students gain sufficient English in order to be able to perform well in each exam. American High School Diploma, however, uses the Scholastic Assessment Test (SAT) as an entrance exam to colleges and universities. Although the SAT assesses maths, reading and writing, it does not mirror a high school curriculum. As the psychologist Steele points out the "SAT is not going to get you very far with predicting who's going to do well in college." He goes on to say that the test measures "only about $18 \%$ of the things that it takes to do well in school." Therefore, it might be the case that schools offering the American High School Diploma focus their attention on helping students prepare for the test as opposed to developing their language skills in preparation for university study. With 
regard to Thanaweya Amma students, they study all academic subjects through the medium of Arabic. English is taught as a compulsory subject. Therefore, being taught all subjects in the first language (L1) will reduce the exposure students get to the second language (L2) and minimise the opportunities for learning and using it. As Phillipson (1992) argues "the more English is taught the better the results" (p.185). In line with Phillipson, it could be argued that the deficiency in the L2 has a profound impact on the Thanaweya Amma students' preparedness for university and on their academic success, hence the reason they have received the lowest mean scores.

\section{Conclusion}

In summary, English proficiency is a determinant of academic success for students who are majoring in Engineering, Business (including Business Administration, Economics and Political Science) and Informatics and Computer Science at the BUE. The research findings of this study revealed that the higher the English proficiency of students on entry to the university the better they will perform in their degree area courses as well as their English levels as they will be able to be fully engaged in the learning process which in turn should result in better performance. Therefore, it is recommended that the institution higher the entry level for English. As shown by the results of this research, such a decision will have important implications for instruction and academic achievement.

\section{References}

Abbad, A. (1988). An Analysis of Communicative Competence Features in English Language Texts in Yemen Arab Republic. PhD Dissertation, University of IIIinois at Urbana-Champaign.

Aina, J. K., Ogundele, A. G., \& Olanipekun, S. S. (2013). Students' proficiency in English language relationship with academic performance in science and technical education. American Journal of Educational Research, 1(9), 355-358.

AlHaddad, S. K., Mohamed, M., \& Al Habshi, S. M. (2004). An exploratory study on English language proficiency and academic performance in the context of globalization of accounting education. Journal of Financial Reporting and Accounting 2(1), 55-71.

Barthe, A. (2012). Campus review: Strewth! Institutions must mind students' language. Times Higher Education, June issue.

Department of Education, Employment and Workplace Relations (DEEWR). (2009). Good Practice Principles for English language proficiency for international students in Australian universities. Canberra, Australia.

Dooey, P. (1999). An investigation into the predictive validity of the IELTS Test as an indicator of future academic success. In K. Martin, N. Stanley, \& N. Davison (eds.), Teaching in the Disciplines/Learning in Context. Proceedings of the $8^{\text {th }}$ Annual Teaching Learning Forum, University of Western Australia, pp.114-118.

Fakeye, D. (2014). English language proficiency as a predictor of academic achievement among EFL students in Nigeria. Journal of Education and Practice 5(9), 38-41.

Feast, V. (2002). The impact of JELTS scores on performance at university. International Education Journal 3(4), 7085.

Hill, K., Storch, N., \& Lynch, B. 1999. A Comparison of IELTS and TOEFL as predictors of academic success. English Language Testing System Research Reports 2, 52-63.

Jekayinfa, A. A. (1991). Competence in the language of instruction as a predictor of performance in secondary school history.Ilorin Journal of Education 11, 103-112.

Kong, J., Powers, S., Starr, L., \& Williams, N. (2012). Connecting English language learning and academic performance: A Prediction Study of the American Educational Research Association. Vancouver, British Columbia, Canada.

Kumar, P. (2014). Effect of proficiency in English language on academic performance of post graduate management students of Marathwada region (Maharashtra), India. IOSR Journal of Business and Management 16(5), 2319-7668.

Maleki, A., \& Zangani, E. (2007). A survey on the relationship between English language proficiency and the academic achievement of Iranian EFL students. Asian EFL Journal, 9(1), 86-96.

Mukattash, L. (1983). The problem of difficulty in foreign language learning. In E. Dahiyat, \& M. Ibrahim (eds.), The First Conference on the Problems of Teaching English Language and Literature at Arab Universities. University of Jordan, Amman, Jordan.

Murray, N. L. (2010). Conceptualising the English language needs of first year university students. International Journal of the First Year in Higher Education 1(1), 55-64.

Phillipson, R. (1992). Linguistic Imperialism. Oxford: Oxford University Press.

Roche, T., \& Harrington, M. (2013). Recognition vocabulary knowledge as a predictor of academic performance in an English as a foreign language setting. Language Testing in Asia 3(12). http://dx.doi:10.1186/2229-0443-3-12.

Sadeghi, B., Kashanian, N. M., Maleki, A., \& Haghdoost, A. (2013). English language proficiency as a predictor of academic achievement among medical students in Iran. Theory and Practice in Language Studies 3(12), 2315-2321. 
Sahragard, R., Baharloo, A., \& Soozandehfar, S. M. A. (2011). A closer look at the relationship between academic achievement and language proficiency among Iranian EFL students. Theory and Practice in Language Studies 1(12), 1740-1748.

Sahragard, R., \& Baharloo, A. (2009). Fear of success, imposter phenomenon, academic achievement, and language proficiency among some Iranian EFL learners: a correlational study. Iranian EFL Journal Quarterly 3(1), 6-35.

Sivaramana, I., Al Balushib, A., \& Rao, D. H. (2014). Understanding Omani students' (University) English language problems. International Journal of Sciences: Basic and Applied Research (IJSBAR) 13(1), 28-35.

Steele, C. 2001. "Secrets of the SAT." Frontline" Interview in 2001 with Steele. http://www.pbs.org/wgbh/pages/frontline/shows/sats/interviews/steele.html (Accessed July 2014).

Study Connect International. 2014. English language requirements for UK University admission and Student Visa. http://www.studyconnectinternational.com/2014/07/17/ english-language-requirements-for-university-admission-andstudent-visa/ (Accessed August 2014).

Suleiman, S. (1983). Teaching English to Arab students at the university level. In E. Dahiyat, \& M. Ibrahim (eds.), First Conference on the Problems of Teaching English Language and Literature at Arab Universities. University of Jordan, Amman, Jordan.

Wilkinson, L., \& Silliman, E. (2008). Academic language proficiency and literacy instruction in urban settings. In L. Wilkinson, L. Morrow, \& V. Chou (eds.), Improving Literacy Achievement in Urban Schools. Critical Elements in Teacher Preparation, Newark, DL: International Reading Association.

Wilson, J., \& Komba, S. C. (2012). The Link between English language proficiency and academic performance: A pedagogical perspective in Tanzanian secondary schools. World Journal of English Language 2(4). http://dx.doi:10.5430/wjel.v2n4p1.

Win, R. \& Miller, P. W. (2004). The Effects of Individual and School Factors on University Students' Academic Performance. CLMR Discussion Paper Series 04/4. The Centre for Labour Market Research, University of Western Australia, Crawley WA.

Xu, M. (1991).The impact of English-language proficiency on international graduate students' perceived academic difficulty. Research in Higher Education 32(5), 557-570.

Zughoul, M. (1983). The unbalanced program of the English department in the Arab world. In E. Dihayat, \& M. Ibrahim (eds.), First Conference on the Problems of Teaching English Language and Literature at Arab Universities. University of Jordan, Amman, Jordan. 